\title{
Prediction of burning velocity and quenching distance of hydrogen flames
}

\author{
Ali Cemal Benim*, and Björn Pfeiffelmann \\ Center of Flow Simulation (CFS), Department of Mechanical and Process Engineering, Düsseldorf University of Applied Sciences, \\ Münsterstr. 156, D-40476 Düsseldorf, Germany
}

\begin{abstract}
Atmospheric, laminar, stoichiometric, premixed hydrogen-air flames in a diverging channel are investigated by means of Computational Fluid Dynamics. This configuration has been recently used in a series of experimental investigations to determine the burning velocities and quenching distances for premixed flames of different fuels. The purpose of the present investigation is the validation of the prediction procedures for the burning speeds and quenching distances for hydrogen flames by comparing them with these measurements. Global and detailed reaction mechanisms are applied to describe the combustion process. For assuring an adequately fine resolution of the flame fronts, adaptive grid refinement techniques are applied. A reasonable agreement is observed with the experiments, where the detailed and global mechanisms are slightly overpredicting and underpredicting the quenching distance, respectively.
\end{abstract}

\section{Introduction}

Power generation by thermal machinery, including the gas turbine and steam turbine plants, largely depends on combustion. Parallel to the efforts for exploiting new energy sources [1], combustion is still playing an important role in power generation.

Combustion of hydrogen containing fuels plays an especially important role in clean and efficient energy supply. On the one hand, hydrogen is an attractive alternative to store excess renewable energy [2]. On the other hand, the gasification of solid fuels is a good possibility for clean power generation [3]. The gasification product contains significant amounts of hydrogen. Further, there is an increasing trend in hydrogen production by nuclear power plants [4].

Combustion of hydrogen has importance also for safety engineering, since hydrogen has a high diffusivity and its leakage is more likely to be an issue compared to other gases.

Burning hydrogen containing gas in combustion systems is a big challenge. In comparison to other gases, hydrogen has very different material properties, so that even in small percentages, it can largely change the characteristics of the mixture.

A principal problem in premixed combustion systems is the so-called "flashback" [5]. A cause for this is the lower flow speed compared to flame speed, which may be caused by a change in the burner operation. By its high reactivity and flame speed, hydrogen increases the flashback propensity considerably. A measure to prevent flashback is the use of a quenching mesh. Here, the flame propagation is prevented by quenching the flame, mainly by heat loss to walls, when the mesh size is sufficiently small. The distance, where the flame is quenched near the wall is the quenching distance. Although experimental values for quenching distances can be found in the literature [6], there is a need for a better understanding of the phenomenon with respect to the influence of different conditions [7].

Until recently a number of further experimental [8] and theoretical [9] studies were performed on the subject. Computational investigations [10,11] are, however, still rare and bound to simplifications leaving room for further exploration.

In recent years, a special experimental method was applied to measure the burning velocities and quenching distances for premixed flames of different fuels [12-14]. The measurements for a premixed hydrogen flame are taken as the experimental basis for the present paper.

\section{Problem description}

The measurements of Jung et al. [13] are considered. They were based on the use of a water-cooled annular stepwise diverging tube. The varying flow velocity along the tube length, due to the changing flow area, allows the flame to be stabilized at different axial positions corresponding to different channel heights. This provided suitable means for burning speed and quenching distance measurements.

\section{Models}

In the present paper, a stoichiometric hydrogen-air mixture [15] is considered. The transport equations of the chemically reacting mixture are solved, assuming a

\footnotetext{
* Corresponding author: alicemal@prof-benim.com
} 
subsonic flow and an ideal gas behavior $[15,16]$. Buoyancy is neglected. The radiative heat transfer [17] is also neglected. Laminar flames are considered. Thus, modelling errors with respect to the modelling of turbulence [18] and turbulence-chemistry interaction [19] are avoided. Considering the multi-component diffusion, the Soret and Dufour effects are also neglected, in the species transport and energy equations, respectively $[15,16]$.

For the numerical simulations, ANSYS Fluent 18.0 [20]. As Navier-Stokes solver, the SIMPLEC [20] scheme is used. For discretizing the convective terms, a second-order upwind scheme [20] is used. The chemical kinetics software Cantera [21], is also used 1D calculations for verifying different reaction mechanisms.

Flame propagation depends on the material properties. Thus, their accurate modeling is attempted. The specific heat capacities as function of temperature are obtained using a pair of fourth order polynomials [22], for low and high temperature ranges. Transport properties are obtained from the kinetic theory [23,24].

Chemical kinetics rate coefficients are modeled by Arrhenius expressions [15]. A single-step mechanism and three detailed reaction mechanism are considered. The single-step mechanism is that of Marinov et al. [25] (M). The detailed mechanisms are: GRI-Mech 3.0 [26] (GRI), the mechanism of $\mathrm{Li}$ et al. [27] (LI) and the mechanism of Conaire et al. [28] (CON).

\section{Results}

As a basis validation, the propagation speed $\left(\mathrm{S}_{\mathrm{L}}{ }^{0}\right)$ of a 1D flame is calculated with different reaction mechanisms for different equivalence ratios, using Cantera [21]. The results are shown, and compared with the measurements of Taylor [29] and Aung et al. [30] in Figure 1. One can see, that the detailed mechanisms show a very good agreement with each other and a quite fair agreement with the measurements. The single-step mechanism shows a fair agreement with measurements for stoichiometric and lean mixtures (Fig. 1).

Subsequently, a steady, 2D formulation is applied to

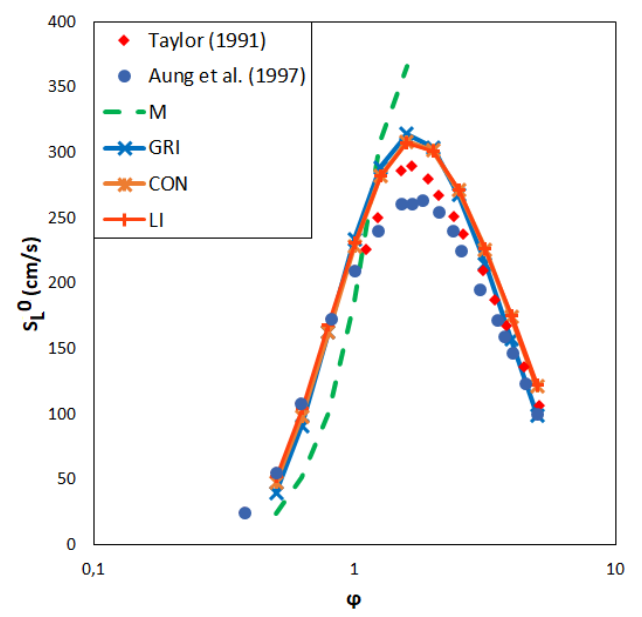

Figure 1. $\mathrm{S}_{\mathrm{L}}{ }^{0}$ as function of $\phi$ for atmospheric, adiabatic, laminar, planar, unstretched hydrogen-air flames: Predictions by different mechanisms compared with measured value predict an atmospheric, laminar, stoichiometric, premixed $\mathrm{H}_{2} /$ Air flame stabilized in a diverging channel.The geometry is sketched in Figure $2(\mathrm{~h}=0.4$ $\mathrm{mm}, \mathrm{H}=4.0 \mathrm{~mm}, \alpha=2^{\circ}$ ). This geometry is not identical with that of the one used in [13]. However, we assume that the differences are not of significance for the results.

At the inlet, a uni-directional flow is prescribed with constant profiles for all relevant variables. At the outlet, the static pressure is prescribed with zero-gradient conditions for other variables. At walls the no-slip condition applies. At the inlet and isothermal walls, the temperature is kept constant at $300 \mathrm{~K}$.

In our previous study [31], it was concluded that a cell size of $0.01 \mathrm{~mm}$ is sufficient for resolving the flame front of a stoichiometric $\mathrm{H}_{2}$ /Air flame, which is taken as reference. A structured baseline grid is generated, first. With an equidistant cell size of $0.1 \mathrm{~mm}$ in the longitudinal direction. In the traversal direction, with 20 equidistant cells in the half-domain 20 the resulting maximum cell size turns out to be $0.1 \mathrm{~mm}$. For resolving the flame front a local grid adaption is used at the flame front to achieve a cell size of 0.01 , locally.

Fields of the temperature, and mass fractions of $\mathrm{H}_{2}$ and $\mathrm{H}_{2} \mathrm{O}$ as predicted by the mechanism $\mathrm{M}$, for $\phi=1.0$, for a prescribed flow rate are displayed as detail plots in Figure 3. One can see that for this case, the flame front is strongly curved (Fig. 3). It can also be observed that it is predicted to be very thin. Cooling by the channel walls can easily be observed in the temperature field (Fig. 3a). Despite the heat loss to the walls, the flame is stabilized at a position in the channel.

The fields of temperature as well as $\mathrm{H}_{2}$ and $\mathrm{H}_{2} \mathrm{O}$ mass fractions predicted by the mechanism LI, for $\phi=1.0$, for the same flow rate (Fig. 3) are displayed as detail plots in Figure 4. One can observe that a strongly curved flame front is also predicted by the mechanism LI. However, the flame stabilization position in considerably downstream compared to that of mechanism M (Fig. 3) implying a lower flame burning velocity. The predicted mass fraction fields of $\mathrm{H}, \mathrm{O}, \mathrm{OH}, \mathrm{HO}_{2}$ by the mechanism LI, for the same case (Fig. 4) are presented in Figure 5, where the distributions of these radials across the flame front can be observed.

Please note that the Flame Propagation Velocities (FPV) for the present configuration cannot directly be compared with $\mathrm{S}_{\mathrm{L}}^{0}$ for several reasons, including the fact that the flames in the present configuration are curved and stretched. FPV is given by the unburnt flow velocity in front of the flame [13] for a steady-state problem. However, the corresponding flow velocity is afflicted with uncertainty. The flow speed varies along the diverging channel (which actually enables a flame stabilization). Jung et al. [13] defined the flow velocity by its area averaged value at a small distance upstream the flame front.

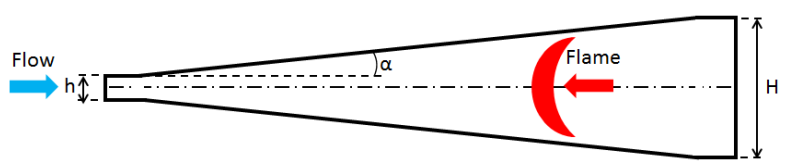

Figure 2. Configuration for flame stabilized in diverging duct 

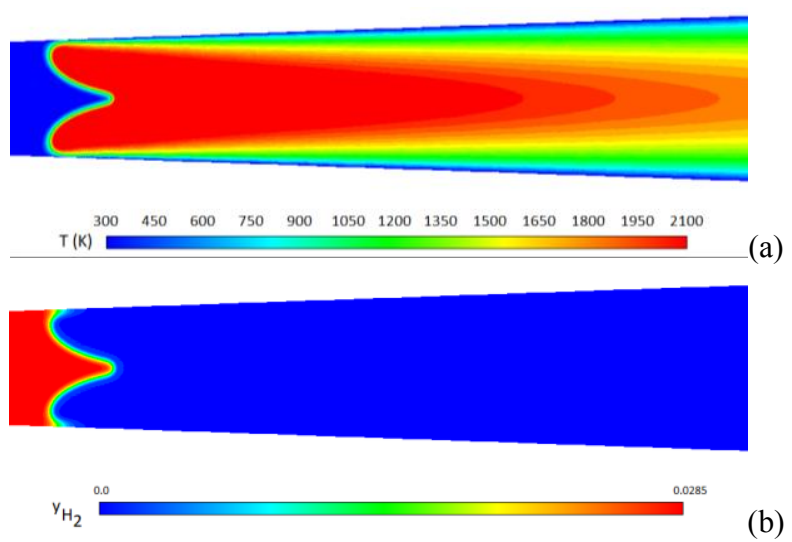

(b)

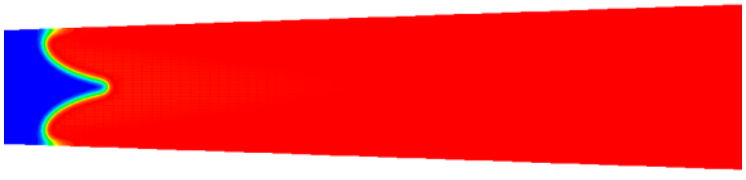

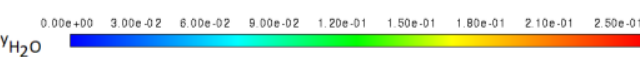

Figure 3. Predicted fields of (a) temperature, (b) $\mathrm{H}_{2}$ mass fraction, (c) $\mathrm{H}_{2} \mathrm{O}$ mass fraction, mechanism $\mathrm{M}, \phi=1.0$ (detail)
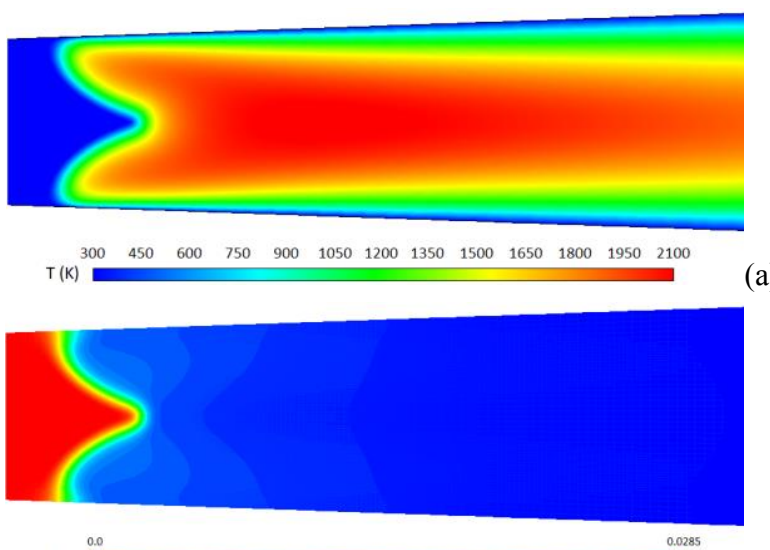

$\mathrm{y}_{\mathrm{H}_{2}}$

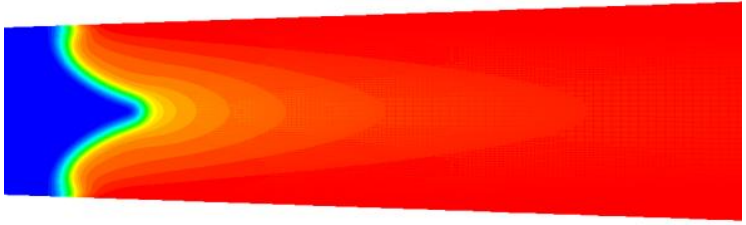

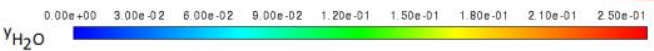

Figure 4. Predicted fields of (a) temperature, (b) $\mathrm{H}_{2}$ mass fraction, (c) $\mathrm{H}_{2} \mathrm{O}$ mass fraction, mechanism $\mathrm{LI}, \phi=1.0$ (detail)

The calculations are performed for different flow rates. With decreasing flow rate, and thus, decreasing flow velocities (compared to the flame speed) the flame front moves upstream in the diverging tube, and gets stabilized at a position, where the flow speed and flame speed are balanced. With the upstream movement of the flame, the corresponding channel width gets smaller.

Using the approach applied by Jung et al. [15], the channel width at the position, where the flame cannot move further upstream by further reductions of the flow rate is identified as the quenching distance.
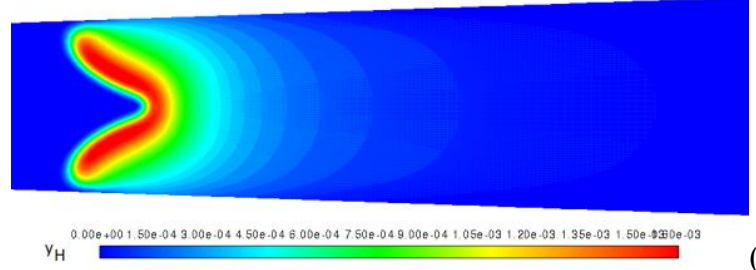

(a)

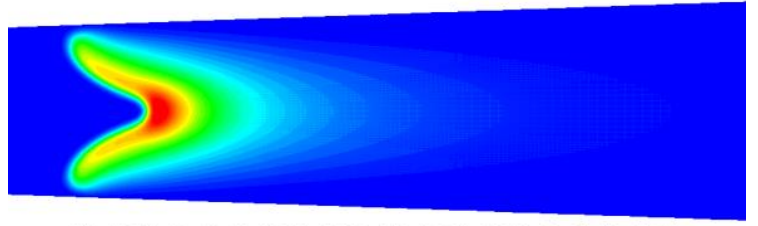

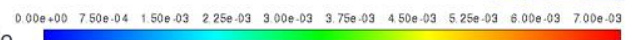

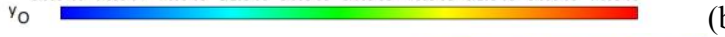

(b)

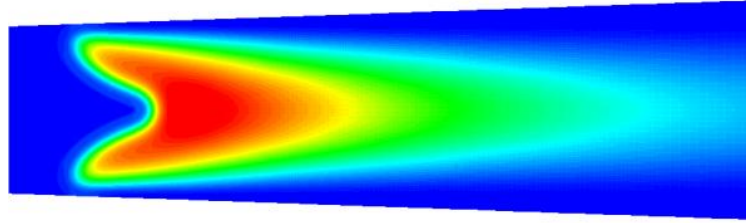

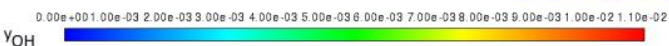

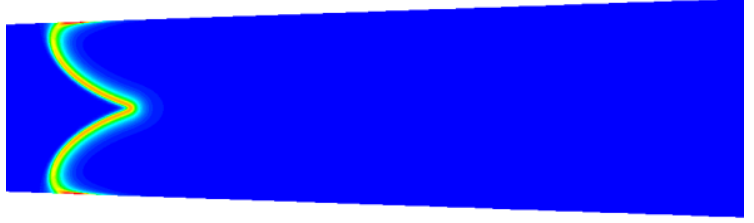

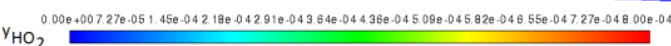

Figure 5. Predicted fields (a) $\mathrm{H}$ mass fr., (b) $\mathrm{O}$ mass fr. (c) $\mathrm{OH}$ mass frac., (d) $\mathrm{HO}_{2}$ mass frac., mechanism LI, $\phi=1.0$ (detail)

The predicted quenching distance $(\delta)$ by the applied two mechanisms (LI, M) are compared with the measurements (EXP) of Jung et al. [13] in Table 1. One can see that the predictions are not reproducing the experimental results exactly but they are quite close to the measurements. The detailed mechanism (LI) slightly overpredicts the measured value, whereas the latter is slightly underpredicted by the single-step reaction mechanism (M). This trend, i.e. the predicted quenching distance by the detailed reaction mechanism to be larger than that of the single-step mechanism was also observed in the previous study [31].

Table 1. Measured [13] and presently predicted quenching distances.

\begin{tabular}{cccc}
\cline { 2 - 4 } & EXP & LI & M \\
\hline$\delta(\mathrm{mm})$ & 0.65 & 0.74 & 0.44 \\
\hline
\end{tabular}

\section{Conclusions}

Atmospheric, laminar, stoichiometric, premixed hydrogen-air flames in a diverging channel are computationally investigated. For the prediction of the quenching distance, a reasonable agreement is observed with the experiments. The detailed mechanism was slightly overpredicting the measured value, while the global mechanism was slightly underpredicting the same. 


\section{References}

1. D.G. Ebling, A. Krumm, B. Pfeiffelmann, J. Gottschald, J. Bruchmann, A.C. Benim, M. Adam, R. Labs, R.R. Herbertz, A. Stunz, "Development of a system for thermoelectric heat recovery from stationary industrial processes", Journal of Electronic Materials, 45(7), pp.3433-3439 (2016)

2. M. Götz, J. Lefebvre, F. Mörs, A. McDaniel Koch, F. Graf, S. Bajohr, R. Reimert, Th. Kolb, "Renewable power-to-gas: a technological and economic review", Renewable Energy, 85, pp.13711390 (2016)

3. S. De, A.K. Agarwal, V.S. Moholkar, B. Thallada (Eds.), Coal and Biomass Gasification, (Springer, Berlin, Germany, 2018)

4. IAEA, "Hydrogen Production Using Nuclear" Energy, IAEA Nuclear Energy Series No. NP-T-4.2, Internat. Atomic Energy Agency, Vienna (2013)

5. A.C. Benim, K.J. Syed, Flashback Mechanisms in Lean Premixed Gas Turbine Combustion, (Academic Press, Cambridge, MA, USA, 2014)

6. B. Lewis, G. von Elbe, Combustion, Flames and Explosions of Gases, $3^{\text {rd }}$ ed., (Academic Press, Orlando, USA 1987)

7. H. Philips, "On the transmission of an explosion through a gap smaller than the quenching distance", Proceedings Royal Society, 7, pp.129-135 (1963)

8. S.Y. Yang, S.H. Chung, H.J. Kim, "Effect of pressure on quenching meshes in transmitting hydrogen in combustion", Nuclear Engineering and Design, 224, pp.199-206 (2003)

9. S.W. Hong, J.H. Song, "Flame-quenching model of the quenching mesh for H2-Air mixtures", Journal of Nuclear Science and Techn., 50, pp.1213-1219 (2013)

10. Z.B. Song, L.J. Wei, Z.Z. Wu, "Effects of heat losses on flame shape and quenching of premixed flames in narrow-channels", Combustion Science and Technology, 180, pp.264-278 (2008)

11. S. Kudriakov, E. Studer, C. Bin, "Numerical simulation of the laminar hydrogen flame in the presence of a quenching mesh", International Journal of Hydrogen Energy, 36, pp.2555-2559 (2011)

12. Z. Liu, N. I. Kim, “An assembled annular stepwise diverging tube for the measurement of laminar burning velocity and quenching distance", Combustion and Flame, 161, pp. 1499-1506 (2014)

13. Y. Jung, M.J. Lee, N.I. Kim, "Direct prediction of laminar burning velocity and quenching distance of hydrogen-air flames using an annular stepwise diverging tube (ASDT)", Combustion and Flame, 164, pp.397-399 (2016)

14. H. Y. Kim, N. I. Kim, "Precise measurement if the length-scale effects on the flame propagation velocity using a compact annular stepwise- diverging-tube (ASDT)", Combustion and Flame, 191, pp.210-212 (2018)

15. S.R. Turns, An Introduction to Combustion, $3^{\text {rd }}$ ed., (McGrawHill, New York, USA, 2012)

16. R.B. Bird, W.E. Stewart, E. N. Lightfoot, Transport Phenomena, $2^{\text {nd }}$ ed., (Wiley, New York, USA, 2002)

17. A.C. Benim, "A finite element solution of radiative heat transfer in participating media utilizing the moment method", Computer Methods in Applied Mechanics and Engineering, 67(1), pp.1-14 (1988)

18. A.C. Benim, M.P. Escudier, A. Nahavandi, A.K. Nickson, K.J. Syed, F. Joos, "Experimental and numerical investigation of isothermal flow in an idealized swirl combustor", International Journal of Numerical Methods for Heat \& Fluid Flow, 20(3), pp.348-370 (2010)

19. A.C. Benim, S. Iqbal. W. Meier, F. Joos, A. Wiedermann, "Numerical investigation of turbulent swirling flames with validation in a gas turbine model combustor", Applied Thermal Engineering, 110, pp. 202-212 (2017)

20. ANSYS $®$ FLUENT, www.ansys.com

21. www.cantera.org

22. R.J. Kee, F.M. Rupley, J.A. Miller, "The Chemkin thermodynamic data base", Sandia Report, SAND87-8215B (1991)

23. R.A. Shevla, "Estimated viscosities and thermal conductivities of gases at high temperatures", NASA Technical Report R-132 (1962)

24. R.C. Reid, J.M. Prausnitz, B.E. Poling, The Properties of Gases and Liquids, $4^{\text {th }}$ ed., (McGrawHill, New York, USA, 1987)

25. N.M. Marinov, C.K. Westbrook, W.J. Pitz, "Detailed and global chemical kinetics model for hydrogen", Report No. UCRL-JC-120677, Lawrence Livermore National Laboratory, CA.

26. combustion.berkeley.edu/gri-mech/

27. J. Li, Z. Zhao, A. Kazakov, F.L. Dryer, "A comprehensive modeling study of hydrogen oxidation", International Journal of Chemical Kinetics, 36, pp.566-575 (2004)

28. M.O. Conaire, H.J. Curran, J.M. Simmie, W.J. Pitz, C.K. Westbrook, "A comprehensive modeling study of hydrogen oxidation", International Journal of Chemical Kinetics, 36, pp.603-622 (2004)

29. S.C. Taylor, "Burning velocity and the influence of flame stretch", Ph.D. Thesis, Univ. Leeds (1991)

30. K.T. Aung, M.I. Hassan, G.M. Faeth, "Flame stretch interactions of laminar premixed hydrogen/air flames at normal temperature and pressure", Combust. Flame, 109, pp.1-24 (1997)

31. B. Pfeiffelmann, A.C. Benim, "Numerical study of the quenching of a laminar premixed hydrogen flame", MATEC Web of Conferences, 240, 01031 (2018) 